\title{
Prenatal chlorpyrifos leads to autism-like deficits in C57Bl6/J mice
}

\author{
Anat Lan ${ }^{1,2}$, Michal Kalimian', Benjamin Amram¹ and Ora Kofman ${ }^{1,2^{*}}$
}

\begin{abstract}
Background: Children are at daily risk for exposure to organophosphate insecticides, of which the most common is chlorpyrifos (CPF). Exposure of pregnant women to CPF was linked to decreased birth weight, abnormal reflexes, reduction in $\mathrm{IQ}$, as well as increased maternal reports of signs of pervasive developmental disorder. The aim of current study was to examine the long term effects of prenatal exposure to CPF in C57BL/6 J (B6) mice with specific focus on social and repetitive behavior.

Methods: B6 female mice were treated with vehicle, $2.5 \mathrm{mg} / \mathrm{kg}$ CPF or $5 \mathrm{mg} / \mathrm{kg}$ of CPF on gestational days 12-15 by oral gavage. On postnatal days (PND's) 6-12 early development and neuromotor ability were assessed by measuring 3 neonatal reflexes in the offspring. In adulthood, PND 90, social behavior was investigated using the social preference, social novelty and social conditioned place preference tasks. Object recognition and restricted interest, measured by the repetitive novel object contact task (RNOC), were also assessed on PN D 90. In order to rule out the possibility that CPF administration induced alterations in maternal care, the dams' behavior was evaluated via the maternal retrieval task.

Results: CPF treatment resulted in delayed development of neonatal reflexes on PND's 6-12. On PND 90, mice treated prenatally with the $5.0 \mathrm{mg} / \mathrm{kg}$ dose exhibited reduced preference towards an unfamiliar conspecific in the social preference test and reduced social conditioned place preference. In the RNOC task, mice exposed prenatally to $2.5 \mathrm{mg} / \mathrm{kg}$ dose of CPF showed enhanced restricted interest. CPF administration did not impair dams' behavior and did not cause memory or recognition deficit as was observed in the object recognition task.
\end{abstract}

Conclusions: Our data indicate that gestational exposure to CPF has long-term deleterious effects on social behavior and limits exploration of novel objects.

Keywords: Autism, Chlorpyrifos, Pesticide, Prenatal, Social deficit, Restricted interest

\section{Background}

Chlorpyrifos (CPF) is one of the most widely-used organophosphate pesticides (OP), for the control of insects in both agriculture and urban communities [1]. Indoor use of CPF was phased out in 2005 in the US [2], and the primary route of human exposure is via ingestion of foods containing CPF residues [3, 4]. In agricultural communities, exposure pathways also include dermal contact and inhalation [5]. Young children, compared to adults, are more susceptible to acute toxicity of CPF [6,7], and this could be explained, in part, by the fact that immature

\footnotetext{
* Correspondence: kofman@bgu.ac.il

'Department of Psychology, Ben-Gurion University of the Negev, P.O.B. 653, Beer-Sheva 84105, Israel

${ }^{2}$ Zlotowski Centre for Neuroscience, Ben-Gurion University of the Negev, Beer-Sheva, Israel
}

(c) The Author(s). 2017 Open Access This article is distributed under the terms of the Creative Commons Attribution 4.0 International License (http://creativecommons.org/licenses/by/4.0/), which permits unrestricted use, distribution, and reproduction in any medium, provided you give appropriate credit to the original author(s) and the source, provide a link to the Creative Commons license, and indicate if changes were made. The Creative Commons Public Domain Dedication waiver (http://creativecommons.org/publicdomain/zero/1.0/) applies to the data made available in this article, unless otherwise stated. hydrolyze CPF $[8,9]$.

$\mathrm{CPF}$ targets the central and peripheral nervous system, acting primarily by inhibiting acetylcholinesterase (AChE), resulting in hyper-stimulation of acetylcholine (ACh). Exposure to CPF was also found to elicit changes in cholinergic and catecholaminergic markers in the brain [10], and transcription factors involved in neural cell replication and differentiation [11], as well as stunted axonal growth [12], suggesting that CPF has non-cholinergic mechanisms of action, as well. In subtoxic doses, that do not cause overt signs of toxicity, CPF caused significant inhibition of DNA and protein synthesis, as well as decreased cell density in forebrain, cerebellum and brainstem of neonatal rats [13]. Subtoxic exposure to CPF was also found to affect 
the expression levels of critical genes involved in fetal brain development, including genes involved in motor abilities, learning [14], neuronal communication, growth and plasticity [15].

The neurotoxic effects and neurodevelopmental outcomes of subtoxic exposure to CPF in humans were evaluated in several studies, which found associations between prenatal exposure and developmental deficits in infancy and childhood. Gestational OP exposure was associated with 1) a reduction in infant body length and weight [16], 2) significantly reduced scores in the Mental Development Index (MDI) at ages 12 and 24 months $[17], 3)$ parental reports of Pervasive Developmental Disorder (PDD) at age 24 months [18], 4) lower scores on the Psychomotor Development Index at 36 months [19], and 5) attention deficits at age 36 months [19] and 5 years [20]. Moreover, in the ongoing longitudinal studies, gestational CPF was associated with lower IQ scores and impaired working memory at about 7 years of age $[17,21,22]$, a deficit that was found mainly in boys [23]. In 7-9 year old children, gestational exposure was associated with impaired social skills in black participants and in boys [24].

These studies establish OPs as a long-term risk factor for developmental disorders, but due to lack of statistical power, prospective studies of gestational exposure in infants are limited in their ability to examine disorders like Autism Spectrum Disorder (ASD) [25]. Studies in laboratory animals can demonstrate the causative relationship between an early exposure to CPF and neurodevelopmental impairments. Another advantage to assessing gestational exposure in laboratory animals is that often epidemiological studies are confounded by differences in rearing, nutrition and living conditions amongst mothers who have high vs low levels of OP metabolites in their urine, which can result from greater consumption of vegetables and fruit [26]. A higher level of OP metabolites in mothers was associated with higher socioeconomic status, ethnicity, and education and better diets, factors which can affect the developmental behavioral measures [27, 28].

Administration of CPF to rodents induced long-term behavioral abnormalities, namely deficits in the righting and geotaxis reflexes in female rat pups and reduced locomotor activity in male rat pups after postnatal exposure to CPF on PND 1-4 [29], enhanced agonistic behavior when encountered with an unfamiliar conspecific in male mice after CPF treatment on GND 15-18 and PND 11-14, and decreased anxiety responses on the plus-maze test in mice exposed to CPF on PND 11-14 [30]. CPF exposure elicited decreased ultrasonic vocalizations (USV) in mouse pups, suggesting an impaired ability to communicate distress to the dam [31], an effect that was also found in male and female mice exposed during gestation to chlorpyrifos oxon [32]. However, this last study did not find long term effects on social preference or social novelty compared to vehicle treated mice. Although these studies suggest isolated signs of ASDlike developmental disorders, they have not been robustly replicated in different studies, possibly due to methodological differences between labs.

The aim of the current study was to test the hypothesis that gestational CPF impairs development in several different domains, including motor development and social behavior. C57BL/6 J (B6) mice were treated with vehicle, $2.5 \mathrm{mg} / \mathrm{kg}$ or $5 \mathrm{mg} / \mathrm{kg}$ of CPF during gestational days $12-15$, a period which corresponds roughly to the second trimester of pregnancy in humans [33]. The doses used in the current study were similar to those used in studies on gestational exposure of CPF in rodents. Previous studies found that 3 or $6 \mathrm{mg} / \mathrm{kg}$ gestational CPF from gestational days 15-18 inhibited serum, but not brain AChE [34, 35] and a similar treatment regimen $(5 \mathrm{mg} / \mathrm{kg}$ gavage on GD 6-10) elicited significant cholinesterase inhibition on PND 1 and 5 in the brain and a more prolonged inhibition in blood and heart [36]. The highest dose of CPF used in the current study was found to elicit $20 \%$ inhibition of AChE in mice exposed during late gestation and postnatally [37].

Exposure to CPF in humans is unintentional, but has been found to be widespread in American [38, 39] and Asian children [40]. Exposure in children occurs via different means such as dust, inhalation, dermal exposure and food and includes a mixture of OP and substances [41]. Hence, investigating teratogenic effects of controlled gestational exposure to CPF enabled us to overcome some of the variability that confounds teratogenic research in humans, with the intention of providing a solid basis for exploring the mechanism of the reported deficits in future research.

In the current study, only male offspring were tested, as males are at higher risk for ASD [42]; however, a study on both sexes is underway in our laboratory. To evaluate pups' early development and neuromotor ability, we tested 3 neonatal reflexes; the righting reflex, negative geotaxis, and cliff avoidance. Social behavior was evaluated in adulthood by tests for Social Preference (SP), preference for a conspecific over an object, Social Novelty (SN), preference for a novel mouse over a familiar mouse and Social Conditioned Place Preference (SCPP), preference for an environment previously conditioned with a social stimulus rather than an environment that was not conditioned with such stimulus. B6 mice have been found to display all three of the above signs of social behavior [43-45]. Repetitive behavior was tested using the Repetitive Novel Object Contact task (RNOC) which was used in the proprionic acid model for autism [46]. Finally, in order to rule out the possibility that the 
maternal behavior of the treated dams was impaired, we examined dams' maternal behavior.

\section{Methods}

Animals and treatment

All experiments were conducted on mice of the B6 inbred strain, using only one mouse per litter. Dams and sires for breeding were purchased from Harlan, Israel. Except for the maternal behavior task, all tests were done on male mice. Animals were maintained in a temperature controlled environment $\left(22 \pm 1{ }^{\circ} \mathrm{C}\right)$ under a 12-h reversed light-dark cycle (21:00-9:00 lights on) and ad libitum food and water. Reflexes were tested on PND 6-12 and behavior in adults was tested on PND 90. The protocols were approved by the Institutional Committee for the Ethical Care and Use of the Animals in Experimentation of Ben-Gurion University of the Negev.

CPF (99.5\% purity, Chem Service, Inc.) or corn oil (Willi Food, Yavneh, Israel) was administered by gavage to pregnant females daily from GND 12 to 15 in a volume of $0.1 \mathrm{ml} / 10 \mathrm{~g}$ body weight using a 22 gauge stainless steel feeding tube (Solomon Instech, Inc.). The gestation of B6 mice is $462.4 \mathrm{~h}$ long, or 19.2 days [47], slightly shorter than that observed in CD-1 mice used in other labs. This period is equivalent to Theiler stages 23-26 of development [48], and more specifically to days 61-84 of human brain cortical development and 50-67 of human brain limbic system development [49].

In the first series of studies, 29 dams were divided into 4 treatment groups: No Treatment, Vehicle (corn oil), 2.5 or $5 \mathrm{mg} / \mathrm{kg}$ CPF. Only one male from each litter was used for each experiment, and no animal was used in more than one experiment, such that the adults in the SP and RNOC studies were siblings of the pups used in the reflex study. The SCPP study was done on a separate cohort of 32 dams, divided into 4 groups, as above. The stimulus mouse housed with the experimental mouse was taken from the same litter, in order to control for familiarity, but was not tested for bedding preference. The maternal care study was a pilot study done on a separate cohort of four female mice per group.

\section{Maternal care/Dams' behavior (PND 5)}

In order to test whether maternal care was impaired by $\mathrm{CPF}$, on PND 5 dams were assessed in the maternal retrieval task. Pups were isolated from their dam, which was left alone in the home cage for $15 \mathrm{~min}$. The pups were kept warm during this interval by placing them on a towel wrapped hot water bottle at $37{ }^{\circ} \mathrm{C}$. Three male pups from the litter were returned to the home cage and placed fixed areas about $8 \mathrm{~cm}$ from the nest. The latency to retrieve all three pups to the nest was scored by an experimenter blind to the treatment.

\section{Assessment of early development and neuromotor behavior (PNDs 6-12)}

To evaluate pups reflex development and neuromotor ability, 3 neonatal reflexes were assessed blindly from PND 6-12 in male pups: The righting reflex, negative geotaxis and cliff avoidance. The data represent the average of 3 trials performed sequentially, at intervals of $1 \mathrm{~min}$. The maximum time allowed per trial was $30 \mathrm{~s}$. The pup was weighed before testing.

\section{Righting reflex}

In this test, each mouse was placed on its back on a flat surface and released. The amount of time required to turn upright with all 4 paws in contact with the surface was recorded on a stopwatch.

\section{Negative geotaxis reflex}

Pups were placed in head-down position on a $25^{\circ}$ inclined surface. They had to complete a $180^{\circ}$ turn and maintain the position for $30 \mathrm{~s}$. Mouse performance was manually ranked on a $1-3$ scale: 1 ) downwards slide, 2) remained in position without turning, 3) $180^{\circ}$ turn within $30 \mathrm{~s}$.

\section{Cliff avoidance reflex}

Each animal was placed on a table edge with the forepaws at the edge and the whiskers and nose extending over the edge. To successfully perform this reflex, the pup had to turn $180^{\circ}$ and turn away from the edge within $30 \mathrm{~s}$. Mouse performance was manually ranked on a 1-4 scale: 1) fell on soft padded surface, 2) remained in position without turning, 3) partial turning, 4) $180^{\circ}$ turn.

\section{Social behavior in adults (PND 90) \\ Social preference (SP) and social novelty (SN)}

In the SP task a mouse was placed in a $24 \times 16 \mathrm{~cm}$ three chambered box in which the two side chambers contained either an unfamiliar conspecific in an overturned plastic container that had holes through which the mice on either side could sniff, but not contact, one another or an identical overturned container with no mouse [50-52]. Mice serving as social stimuli were naïve males from a different untreated litter and had been confined previously to the container so that they were habituated to the procedure and did not try to escape. The mouse being tested was allowed to freely explore the arena for $10 \mathrm{~min}$. Preference towards the conspecific was measured by time spent in each chamber, and number of entries to each chamber. At the end of this trial, after a 1 min interval, during which the experimental mouse was held in the middle chamber, a second mouse was put in the side chamber that had contained the object in the SP test and the SN test started. Once again the 
experimental mouse was allowed to freely explore the three chambers for $10 \mathrm{~min}$ and time spent with each stimulus mouse (familiar or novel) was scored. The sessions were filmed and preference was coded by an observer blind to the treatment condition using Ethovision software.

\section{Social conditioned place preference (SCPP)}

Two male mice from the same litter were housed in a standard home cage with one of two novel types of bedding, either aspen sawdust or shredded paper. Notably, pilot data on mice that did not participate in this study indicated that there was no inherent overall preference for either type of bedding but that individual mice tended to show a preference for one or the other bedding.

The social environment was determined by pretesting the mice for bedding preference, such that for each mouse the 'social' cue was the non-preferred bedding. The following day, the experimental mouse was isolated in a cage that contained its preferred bedding, alternating every $24 \mathrm{~h}$ with a "social" environment, namely housing with a cagemate from the same litter with the non-preferred bedding. Conditioning was carried out over 10 days, alternating daily between the social and isolated conditions. Thus, successful social conditioning would result in a change of preference. Food and water were available ad lib.

The conditioned preference for the two distinct types of bedding was assessed for each mouse using the aforementioned three-chambered apparatus, allowing the mouse to freely explore the box for $20 \mathrm{~min}$ while being filmed from above. Each side contained a cupful of one of the bedding materials spread on the floor of the chamber, counter-balancing the side among animals. Time spent in each chamber was scored via the Ethovision software by an observer blind to the treatment condition.

\section{Repetitive novel object contact task (RNOC) (PND 90)}

This test was designed to evaluate repetitive behaviors towards a novel object [38]. Each mouse was placed in a round $40 \mathrm{~cm}$ diameter arena and underwent $5 \mathrm{~min}$ habituation on three consecutive days. One day following habituation, the mouse was placed again in the arena that now contained three novel objects, constructed from several Lego-like blocks, which were placed equidistant from one another. Each object was constructed from 2 to 3 blocks about 5-6 square centimeters in area, differing in shape. The mouse was allowed to freely explore the arena and the objects for $5 \mathrm{~min}$. Time spent engaging in exploration of the objects was analyzed via Ethovision software. Object positions were counterbalanced and after every trial, the arena and objects were cleaned.

\section{Object recognition (PND 90)}

In order to rule out the possibility that exposed mice had a more global impairment that affected their recognition memory, object recognition was examined. The ability of animals to discriminate between objects requires recognition of the previously explored object, and detection of the differences between the objects [53]. The object recognition task was performed in a plastic circular $53 \mathrm{~cm}$ in diameter apparatus. Mice were habituated to the arena and to two identical Lego-like objects that were placed in it for 3 consecutive days, for $15 \mathrm{~min}$ each time. On the fourth day, one object was replaced by a novel, different shape, Lego-like object that was located in the exact same place. Object recognition was tested in a $10 \mathrm{~min}$ trial. Mouse performance was scored by an experimenter blind to the manipulation.

\section{Statistical analysis}

Data were analyzed using parametric analysis of variance (ANOVA). For the reflexes, a repeated measure ANOVA was conducted for the effect of treatment (between subjects) and day (within subjects) for days 6-12. For the tests conducted in adults, ANOVA was conducted for the effect of prenatal treatment for each of the dependent variables, followed by post hoc comparisons between the CPF groups and each of the two control groups. Effect size is shown as partial eta squared.

\section{Results}

Early development and neuromotor behavior (PND's 6-12) Body weight

A two-way ANOVA with repeated measures was conducted for the effect of Age (PND 6-12) and Treatment (NT-No Treatment, Vehicle, $2.5 \mathrm{mg} / \mathrm{kg}$ CPF, or $5 \mathrm{mg} / \mathrm{kg} \mathrm{CPF}$ ) on body weight revealed the expected significant effect of Age, $\mathrm{F}(6150)=213.60, p<.000001$, indicating growth of the pups, no main effect of Treatment $F(3,25)=1.41$, n.s., but a significant interaction between Age and Treatment, $F(18,150)=2.72$, $p<.005)$. The mean weight of the groups was compared using the Least Significant Difference post hoc test in order to see if CPF exposure significantly affected weight gain. The LSD test revealed that on PND 10-12, the group exposed to $5 \mathrm{mg} / \mathrm{kg}$ in utero had a higher average weight than the group that had been exposed to $2.5 \mathrm{mg} / \mathrm{kg}$ CPF in utero and on PND 11-12, the $5 \mathrm{mg} / \mathrm{kg}$ group weighed more than the group treated with oil vehicle. However, on the days when reflexes were impaired (see below) there were no group differences in weight (Table 1). 
Table 1 Mean (SEM) daily body weight (gr) of pups during reflex testing

\begin{tabular}{llllllll}
\hline DAY & 6 & 7 & 8 & 9 & 10 & 11 & 12 \\
\hline No Treatment & $4.13(0.19)$ & $4.29(0.61)$ & $4.71(0.63)$ & $5.11(0.59)$ & $5.56(0.58)$ & $5.98(0.70)$ & $6.47(1.0)$ \\
Vehicle & $3.6(0.49)$ & $3.85(0.70)$ & $4.25(0.69)$ & $4.8(0.76)$ & $5.19(0.74)$ & $5.48(0.79)$ & $5.89(0.87)$ \\
CPF 2.5 mg/kg & $3.13(0.29)$ & $3.63(0.46)$ & $4.06(0.74)$ & $4.58(1.19)$ & $4.98(1.31)$ & $5.36(1.27)$ & $5.76(1.39)$ \\
CPF $5 \mathrm{mg} / \mathrm{kg}$ & $3.53(0.62)$ & $4.01(0.76)$ & $4.56(0.74)$ & $5.18(0.80)$ & $6.02(0.77)$ & $6.48(0.87)$ & $6.95(0.93)$ \\
\hline
\end{tabular}

\section{Righting reflex}

A two-way ANOVA for the effects of Treatment $x$ Age (repeated measure) was conducted on the daily score for each reflex. There was a significant main effect of Treatment, $\mathrm{F}(3,25)=9.63, p<.001, \eta^{2} \mathrm{p}=.54$, and the expected effect of Age, indicating the reduction in righting time as the mice matured, $\mathrm{F}(6150)=57.87, p<.00001, \eta^{2} \mathrm{p}=.46$. Notably, the CPF treatment delayed the development of the righting reflex as seen by the significant interaction between Age and Treatment, $\mathrm{F}(18,150)=3.22, p<.0005, \eta^{2}$ $\mathrm{p}=.28$. The mice treated with $2.5 \mathrm{mg} / \mathrm{kg}$ or $5 \mathrm{mg} / \mathrm{kg} \mathrm{CPF}$ had slower righting reflexes than the Vehicle and NT control groups on PND 6 and 7. The higher dose of CPF also led to a slower righting reflex compared to both control groups on PND 8 and compared to the Vehicle-treated control group on PND 9 (Fig. 1a).

\section{Negative geotaxis}

The two-way ANOVA revealed a significant effect of Treatment, $\mathrm{F}(3,25)=14.91, p<.0001, \eta^{2} \mathrm{p}=.63$ and the expected maturation effect reflected by the significant effect of Age, $F(6,150)=28.07, p<.000001, \eta^{2} p=.53$. The interaction was not significant, $\mathrm{F}(18,150)=1.52$, n.s. Post hoc least significant difference (LSD) comparisons confirmed that both CPF-treated groups had lower average scores on the negative geotaxis reflex than the Vehicle and NT control groups. The difference between the two doses of CPF was not statistically significant, $(p=.06)$, but suggested a trend to a greater effect with the higher dose.

\section{Cliff avoidance}

A main effect of Treatment was found, $F(3,25)=13.52$, $p<.00005, \eta^{2} \mathrm{p}=.64$, as well as the expected effect of

\section{A- Righting reflex \\ B- Negative Geotaxis \\ C- Cliff Avoidance}
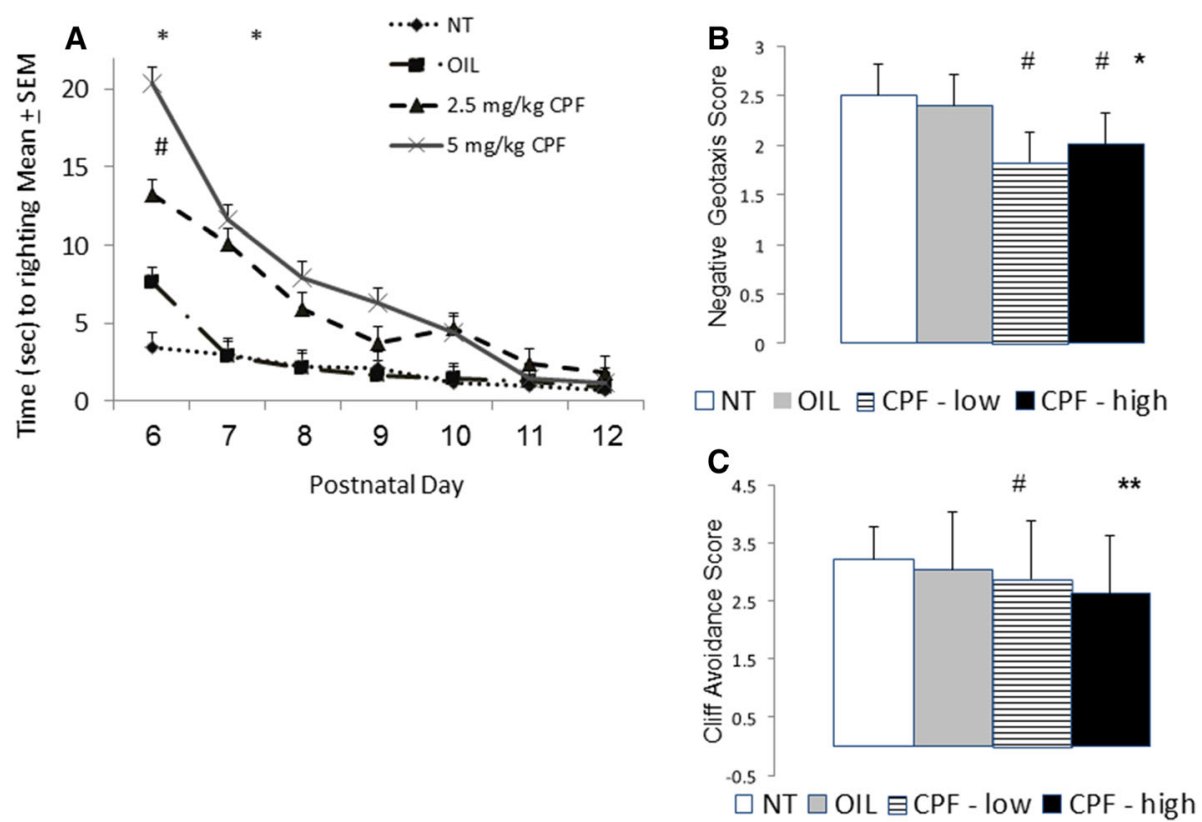

Fig. 1 Postnatal righting reflex (a), negative geotaxis reflex (b) and cliff avoidance reflex (c) in pups whose dams were given no treatment (NT), or gavaged with Vehicle, or 2.5 or $5 \mathrm{mg} / \mathrm{kg}$ CPF in oil once daily on GD12-15. The number of pups per groups was NT $=8, \mathrm{VEHICLE}=7,2.5 \mathrm{mg}$ $\mathrm{CPF}=6,5 \mathrm{mg} / \mathrm{kg}=8$. Statistically significant differences are marked as follows: $\mathbf{a} * p<.05$ compared to NT and VEHICLE. \# $p<.05$ compared to NT and VEHICLE for $5 \mathrm{mg} / \mathrm{kg}$ CPF. $P<.055 \mathrm{mg} / \mathrm{kg}$ CPF Vs VEHICLE. $\mathbf{b}$ Lines represent significant differences $p<.05 . \mathbf{c}^{*} p<.05$ vs each of the other groups. \#p<.05 compared to NT 
Age, $\mathrm{F}(6,150)=16.72, p<.000001, \eta^{2} \mathrm{p}=.40$. The interaction was not significant, $F(18,150)=1.21$, n.s. Post hoc LSD comparisons confirmed that during the testing period the average score was lower in the $5 \mathrm{mg} / \mathrm{kg}$ CPFtreated mice compared to the NT, Vehicle and $2.5 \mathrm{mg} / \mathrm{kg}$ CPF groups. The mice pretreated with $2.5 \mathrm{mg} / \mathrm{kg}$ CPF showed lower scores compared to the NT group, but not compared to the vehicle control group $(p=.07)$, although there was a clear trend suggesting an impairment (Fig. 1c).

\section{Social behavior in adults (PND 90)}

\section{Social preference and social novelty}

In the SP task, a significant interaction between the time spent in each chamber (mouse vs object) and Treatment (NT, Vehicle, 2.5 or $5 \mathrm{mg} / \mathrm{kg}$ CPF) was found, $\mathrm{F}(3,20)=$ 3.36, $p<.05, \eta^{2} \mathrm{p}=.33$. Post hoc comparisons revealed that mice treated with $5 \mathrm{mg} / \mathrm{kg}$ of CPF spent less time with another conspecific compared to Vehicle and NT groups, $p<.05$ (Fig. 2a). We also found a significant interaction between the number of entries to the Side and Treatment, $\mathrm{F}(3,20)=5.36, p<.01, \eta^{2} \mathrm{p}=.45$. Post

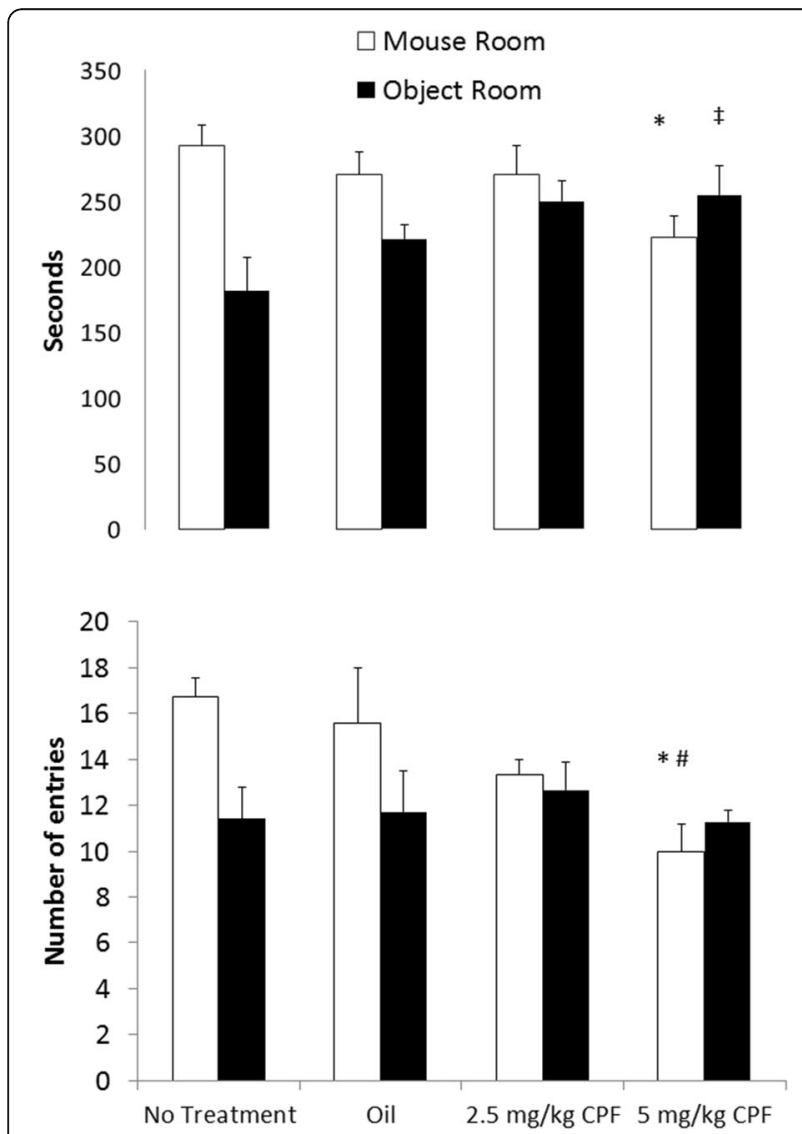

Fig. 2 Social preference Mean + SEM time in seconds (top) and number of entries (bottom) into the side containing the novel mouse compared to the side with the inanimate object. ${ }^{*} p<.05$ compared to the NT and Vehicle groups. The number of mice per group is NT, Vehicle and $5 \mathrm{mg} / \mathrm{kg}=7$ and $2.5 \mathrm{mg} / \mathrm{kg}=3$ hoc comparisons revealed significant differences in the number of entries to the mouse room between the high CPF group and the Vehicle and NT groups. There was no significant difference in the amount of time spent in the object chamber between the Vehicle and either the high CPF, $F(1,20)=0.88$, n.s., or low CPF group, $F(1,20)=.37$ (Fig. 2b).

In the $\mathrm{SN}$ task, however, there was no significant main effect of Side (familiar vs novel mouse), although there was the expected trend to prefer the novel mouse over the familiar mouse $\mathrm{F}(1,16)=3.36, p=0.08$. There was no effect of Treatment (NT, Vehicle, 2.5 or $5.0 \mathrm{mg} / \mathrm{kg} \mathrm{CPF}$ ), $\mathrm{F}(3,16)=1.78$, n.s. The interaction between Side and Treatment was not significant, $F(3,16)=1.23$, n.s. (Table 2), suggesting that although there was a tendency to prefer the novel mouse, this tendency was not significantly affected by the prenatal CPF treatment.

\section{Social conditioned place preference}

Since we used a biased SCPP paradigm, our dependent variable was the difference between the percent of time spent with the initially non-preferred bedding prior to and following social conditioning. The change in preference was compared among the three treatment groups and was found to be affected by CPF, F $(3,28)=2.94$, $p=.05 . \eta^{2} \mathrm{p}=.24$. Post hoc comparisons revealed that the Vehicle control group showed a higher change in conditioned social bedding preference than each of the CPF exposed groups $(p<.05)$, and the difference between the NT and the CPF groups showed a strong trend towards statistical significance $(p=.08$ for $2.5 \mathrm{mg} / \mathrm{kg}$ and $p=.053 \mathrm{for} 5 \mathrm{mg} / \mathrm{kg}$ ) (Fig. 3).

\section{Repetitive novel object contact task (RNOC) (PND 90)}

A main effect for CPF dose was found, for the ratio of time the mouse spent with its preferred object in relation to total time exploring the 3 objects $\mathrm{F}(2,22)=3.48, p<.05$, $\eta^{2} \mathrm{p}=.24$. Post hoc comparisons revealed a significant difference between mice exposed to $2.5 \mathrm{mg} / \mathrm{kg}$ and the vehicle group, $p<.5$. (Fig. 4).

No difference was found between groups for the total amount of time spent within $1 \mathrm{~cm}$ of the objects, $\mathrm{F}$ $(2,22)=1.57$, n.s. or the time spent with the mouse's preferred object, the object with which the mouse spent the

Table 2 Mean + SEM time in seconds spent in chamber containing the familiar mouse and the novel mouse in the Social Novelty Test

\begin{tabular}{lll}
\hline Group/Time & Familiar mouse & Novel mouse \\
\hline No Treatment & $207.923(9.96)$ & $310.306(9.16)$ \\
Vehicle & $203.628(9.61)$ & $327.156(8.20)$ \\
CPF $2.5 \mathrm{mg} / \mathrm{kg}$ & $257.02(6.18)$ & $254.333(4.97)$ \\
CPF $5 \mathrm{mg} / \mathrm{kg}$ & $241.18(18.68)$ & $243.237(20.36)$ \\
\hline
\end{tabular}




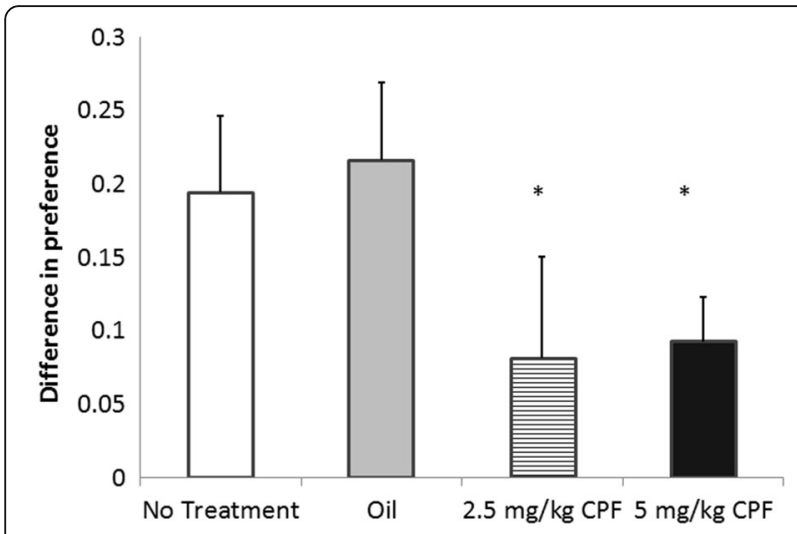

Fig. 3 Socially conditioned change in preference for a previously non-preferred bedding (Mean + SEM). * $p<.05$ compared to the Vehicle group. Number of mice per group was $N T=8$; Vehicle $=7$; $2.5 \mathrm{mg} / \mathrm{kg}=5 ; 5 \mathrm{mg} / \mathrm{kg}=12$

most time, $F(2,22)=1.59$, n.s. suggesting that the enhanced object preference in the CPF group was not due to a motor or sensory deficit. Of the three objects, all were preferred by some of the mice, with one of the objects being preferred by 12 of the 25 mice, including about half the mice in each group. The other two objects were favored by 6 and 7 mice from the sample of 25 .

\section{Object recognition (PND 90)}

Time spent in proximity of $2 \mathrm{~cm}$ to the object was computed for every object. The ratio between the time spent with the novel object relative to total time spent with the familiar and novel objects was calculated: $\mathrm{F}(2,15)=0.305$,

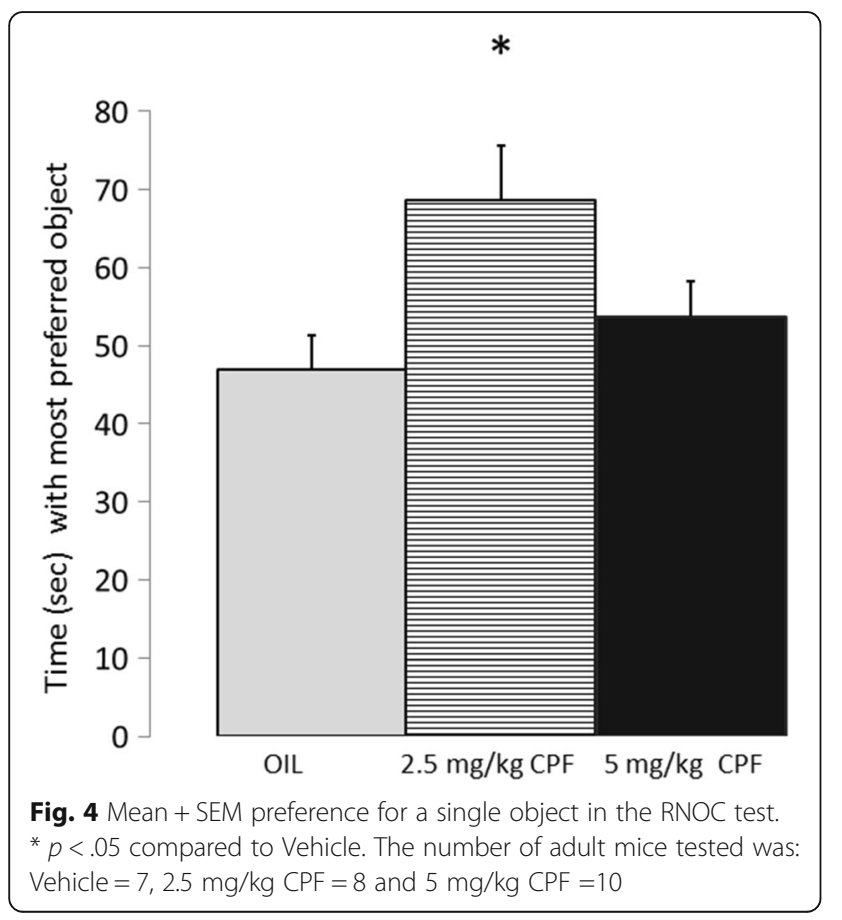

ns. Differences between mice treated with vehicle (mean $=0.62, \mathrm{SEM}=0.017), 2.5 \mathrm{mg} / \mathrm{kg}$ CPF $($ Mean $=0.695$, SEM $=0.022)$ and $5 \mathrm{mg} / \mathrm{kg}$ CPF $($ Mean $=0.613, \mathrm{SEM}=0.063)$ treated mice were not found. There were no differences between groups in the total amount of time spent with objects: $\mathrm{F}(2,15)=1.06$, ns, suggesting that gestational $\mathrm{CPF}$ did not affect recognition or memory ability.

\section{Maternal care (PND 5)}

The latency to retrieve each pup was compared by 2way ANOVA with pup as a repeated measure. The latency for one dam for pup 2 (Vehicle group) was missing, so that the group average was substituted for that mouse. A significant effect of PUP was found, indicating that the first pup was retrieved more slowly than the other two pups, $\mathrm{F}\left(2,28=7.46, p<.01, \eta^{2} \mathrm{p}=.35\right.$. There was no significant difference between groups in the maternal retrieval task and no interaction between group and pup ( $\mathrm{F}<1$ in both analyses), suggesting that maternal care was not impaired in dams that received CPF by gavage (Table 3).

\section{Discussion}

Taken together, our results indicate that gestational CPF interferes with early neuromotor development, causes deficits in social behavior and increases restricted interest in adulthood. Notably, although long-term effects of early exposure to CPF or chlorpyrifos oxon on USV emission and social interactions have been reported [31], this is the first study to demonstrate a consistent pattern of both spontaneous and learned social behavior as well as restricted interest in adults that had been exposed to CPF during gestation. Moreover, the observed anomalies do not appear to be related to maternal care or to a memory deficit.

In the early stages of postnatal development, gestational exposure to CPF resulted in delayed development of neonatal reflexes; however, the observed anomalies in all three neonatal reflexes were transient, as was the weight difference which was not evident during the period in which the deficits in reflexes were apparent. At 12 days of age, mice that were exposed to CPF performed as well as mice that were not exposed, suggesting that these basic motor functions were not impaired at the time the social and RNOC behaviors

Table 3 Maternal pup retrieval test

\begin{tabular}{llll}
\hline & Retrieval pup1 & Retrieval pup2 & Retrieval pup3 \\
\hline Vehicle $(\mathrm{N}=4)$ & $79.09(11.95)$ & $10.59(0.99)$ & $13.99(1.68)$ \\
CPF $2.5 \mathrm{mg} / \mathrm{kg}(\mathrm{N}=9)$ & $83.81(8.6)$ & $29.45(5.01)$ & $24.76(4.21)$ \\
CPF $5 \mathrm{mg} / \mathrm{kg}(\mathrm{N}=4)$ & $80.12(9.03)$ & $35.25(8.45)$ & $18.13(4.78)$ \\
\hline
\end{tabular}

Time (sec) required to retrieve 3 pups in dams treated with CPF or vehicle on gestational days 12-15. Data are indicated as Mean + SEM 
were tested in adults. Our results are in line with results from Engel et al., [17], who found a similar deficit in neuromotor development in newborn infants, who displayed abnormal reflexes after in utero and early postnatal exposure to organophosphates [54]. Infants at high risk or who were later diagnosed with autism spectrum disorders (ASD) showed more deficits in reflexes and spontaneous motor movement during childhood than typically developing children [55]. Although delays in the development of reflexes are by no means specific, the pattern of developmental and adult deficits that emerged from this study warrants further investigation of the effects of gestational exposure to $\mathrm{CPF}$ on social functioning and restrictive interest at different ages.

In adults, we found that mice that were treated with $5 \mathrm{mg} / \mathrm{kg}$ CPF did not show preference towards a conspecific in the SP task, which assesses sociability in mice, and has been validated in genotypes related to autism in humans such as neural cell adhesion molecule null mice, neuroglinin-4 null mice and fragile $\mathrm{X}$ mental retardation protein deficient mice [56-58]. In contrast to our findings following gestational $\mathrm{CPF}$, postnatal exposure to CPF on PND 11-14, did not impair social preference SP [45]. Together, these data suggest that different behaviors are affected by CPF exposure in different critical periods from gestation throughout the preweanling period $[29,59,60]$ and that the effects of prenatal exposure to CPF do not completely overlap with those of postnatal exposure. Critical periods of sensitivity to the detrimental effects of developmental exposure to $\mathrm{CPF}$ on social behavior will require further investigation in a single study that compares different treatment regimens. Although the mice that had been exposed to CPF did not show a deficit in the SN task, this could be related to the fact that they did not show a preference for the supposedly familiar mouse on the SP task which preceded the SN task. The lack of preference for the mouse over the inanimate object precludes the ability to subsequently recognize this same mouse as "familiar" in the $\mathrm{SN}$ test. Thus, the absence of a CPF effect in the SN task is consistent with their "failure" to prefer to spend time with a conspecific over an object.

In the SCPP task, in contrast to both control groups, mice that were treated with CPF failed to show a sociallyconditioned change of preference towards bedding that was paired with a social stimulus ('social environment'). The fact that control groups did reverse their bedding preference indicates that social conditioning is a powerful reinforcer. The resistance of CPF- treated mice to preference change is reminiscent of ASD-like exaggerated need for routine. Further studies are required to determine if CPF-treated mice are able to switch their preference following conditioning for a non-social reward.
The mechanism of the long-term effects of gestational CPF remain undetermined. CPF administration during development alters the levels of monoamine systems and was found to modify the expression of numerous genes, many of which are involved in neuronal and glial development and other regulated processes unrelated to the $\mathrm{AChE}$ inhibition [61]. Another likely mechanism could involve alterations in the neurohypophysis hormones, oxytocin and vasopressin, which are known to affect social behavior and repetitive or stereotyped behaviors [62, 63]. Gestational, but not postnatal CPF treatment induced a significant elevation in hypothalamic oxytocin (OT) and concomitant decrease in arginine vasopressin (AVP) in male, but not female adult mice [64]. The behavioral tests in the current study indicate that gestational CPF may lead to long-term deficits in social behavior and repetitive behavior, supporting findings linking pervasive developmental disorder symptoms in 24 and 36 month old children to gestational OP exposure $[18,19]$. Further research is required to examine the biological underpinnings of these deficits.

\section{Conclusions}

This study indicates that gestational exposure to CPF caused delayed motor development, impaired conditioned and innate social behaviors and increased restricted interest. This is the first study to report long-term effects of developmental exposure to CPF on restricted interest and social behavior in the same cohort of mice. Notably, these abnormalities are similar to those manifested in infants and toddlers whose mothers had been exposed to OP's, such as abnormal reflexes and PDD (e.g., [12]). Since human research is limited and inevitably confounded by subjects' personal history and the fact that subjects are exposed to a mixture of pesticides, this study provides a basis on which to pursue further exploration of the neurobiological mechanisms underlying the behavioral deficits. Several possible mechanisms are likely to be relevant [65]. A recent imaging study found an association between prenatal exposure to $\mathrm{CPF}$ and smaller volume of several prefrontal cortical brain areas involved in regulating emotional behavior in 7 year old children [66], suggesting that morphological studies might shed light on the observed changes in behavior. Gestational chlorpyrifos oxon at doses that inhibited AChE by approximately $85 \%$ [32], appears to mitigate some of the behavioral or structural deficits found in mice expressing low levels of reelin, suggesting that reelin might be relevant for the long-term effects of chlorpyrifos exposure [67]. While the current study does not reveal the underlying mechanism, it demarcates a multi-faceted ASD-like behavioral profile in male mice following gestational exposure to CPF. Future studies should focus on reversal of the behavioral changes and analysis of morphological changes to the brain, as well as exploring the role of sex hormones which are known to be affected by CPF [68]. 


\section{Abbreviations}

AChE: Acetylcholinesterase; ANOVA: Analysis of variance; ASD: Autism spectrum disorder; CPF: Chlorpyrifos; OP: Organophosphate pesticides; PDD: Pervasive developmental disorder; PND: Postnatal day; RNOC: Repetitive novel object contact; SCPP: Social conditioned place preference; SN: Social novelty; SP: Social preference

\section{Acknowledgements}

Not applicable.

\section{Funding}

Funded by grant 1530/14 from the Israel Science Foundation to OK.

\section{Availability of data and materials}

Please contact the author for a link to the raw data.

\section{Authors' contributions}

AL and OK designed the study, analyzed data and wrote the article. AL carried out the studies on pups and adult mice. MK participated in the restricted interest study and data analysis; BA participated in the social conditioned place preference study. All authors read and approved the final manuscript.

\section{Competing interests}

The authors declare that they have no competing interests.

\section{Consent for publication}

Not applicable.

\section{Ethics approval}

The protocols were approved by the Institutional Committee for the Ethical Care and Use of the Animals in Experimentation of Ben-Gurion University of the Negev. Protocols number: IL48-10-2010 \& IL66-11-2013.

\section{Publisher's Note}

Springer Nature remains neutral with regard to jurisdictional claims in published maps and institutional affiliations.

Received: 9 September 2016 Accepted: 14 April 2017 Published online: 02 May 2017

\section{References}

1. Eaton DL, Daroff RB, Autrup H, Bridges J, Buffler P, Costa LG, Coyle J, McKhann G, Mobley WC, Nadel L, Neubert D, Schulte-Hermann R, Spencer PS. Review of the toxicology of chlorpyrifos with an emphasis on human exposure and neurodevelopment. Crit Rev Toxicol. 2008;38 Suppl 2:1-125. doi:10.1080/10408440802272158.

2. Saunders M, Magnanti BL, Correia Carreira S, Yang A, Alamo-HernÃ indez U, Riojas-Rodriguez H, Calamandrei G, Koppe JG, Krayer vK, Keune H, Bartonova A. Chlorpyrifos and neurodevelopmental effects: a literature review and expert elicitation on research and policy. Environ Health. 2012;11(1):1-11. doi:10.1186/1476-069X-11-S1-S5.

3. Kawahara J, Yoshinaga J, Yanagisawa Y. Dietary exposure to organophosphorus pesticides for young children in Tokyo and neighboring area. Sci Total Environ. 2007;378(3):263-8. doi:10.1016/j.scitotenv.2007.02.005

4. Morgan MK, Sheldon LS, Jones PA, Croghan CW, Chuang JC, Wilson NK. The reliability of using urinary biomarkers to estimate children's exposures to chlorpyrifos and diazinon. J Expo Sci Environ Epidemiol. 2011;21:280-90. doi:10.1038/jes.2010.11.

5. Rosas LG, Eskenazi B. Pesticides and child neurodevelopment. Curr Opin Pediatr. 2008;20(2):191-7. doi:10.1097/MOP.0b013e3282f60a7d.

6. Landrigan PJ. Children as a vulnerable population. Int J Occup Med Environ Health. 2004;17(1):175-7.

7. Grandjean P. Only one chance. How environmental pollution impairs brain development - and how to protect the brains of the next generation. New York: Oxford University Press; 2013.

8. Cole TB, Jampsa RL, Walter BJ, Arndt TL, Richter RJ, Shih DM, Tward A, Lusis AJ, Jack RM, Costa LG, Furlong CE. Expression of human paraoxonase (PON1) during development. Pharmacogenetics. 2003;13(6):357-64. doi:10.1097/01.fpc.0000054092.48725.30.
9. Holland N, Furlong C, Bastaki M, Richter R, Bradman A, Huen K, Beckman K, Eskenazi B. Paraoxonase polymorphisms, haplotypes, and enzyme activity in Latino mothers and newborns. Environ Health Perspect. 2006;114(7):985-91.

10. Dam K, Garcia SJ, Seidler FJ, Slotkin TA. Neonatal chlorpyrifos exposure alters synaptic development and neuronal activity in cholinergic and catecholaminergic pathways. Brain Res Dev Brain Res. 1999;116(1):9-20.

11. Crumpton TL. Developmental neurotoxicity of chlorpyrifos in vivo and in vitro: effects on nuclear transcription factors involved in cell replication and differentiation. Brain Res. 2000;28:; doi:10.1016/S0006-8993(99)02357-4.

12. Yang D, Howard A, Bruun D, Ajua-Alemanj M, Pickart C, Lein PJ. Chlorpyrifos and chlorpyrifos-oxon inhibit axonal growth by interfering with the morphogenic activity of acetylcholinesterase. Toxicol Appl Pharmacol. 2008;228(1):32-41.

13. Whitney KD, Seidler FJ, Slotkin TA. Developmental neurotoxicity of chlorpyrifos: cellular mechanisms. Toxicol Appl Pharmacol. 1995;134(1):53-62.

14. Moreira EG, Yu X, Robinson JF, Griffith W, Hong SW, Beyer RP, Bammler TK, Faustman EM. Toxicogenomic profiling in maternal and fetal rodent brains following gestational exposure to chlorpyrifos. Toxicol Appl Pharmacol. 2010;245(3):310-25. doi:10.1016/j.taap.2010.03.015.

15. Stapleton AR, Chan VT. Subtoxic chlorpyrifos treatment resulted in differential expression of genes implicated in neurological functions and development. Arch Toxicol. 2009:83(4):319-33. doi:10.1007/s00204-008-0346-2.

16. Whyatt RM, Camann D, Perera FP, Rauh VA, Tang D, Kinney PL, Garfinkel R, Andrews $\mathrm{H}$, Hoepner L, Barr DB. Biomarkers in assessing residential insecticide exposures during pregnancy and effects on fetal growth. Toxicol Appl Pharmacol. 2005;206(2):246-54. doi:10.1016/j.taap.2004.11.027.

17. Engel SM, Wetmur J, Chen J, Zhu C, Barr DB, Canfield RL, Wolff MS. Prenatal exposure to organophosphates, paraoxonase 1, and cognitive development in childhood. Environ Health Perspect. 2011;119(8):1182-8. doi:10.1289/ehp.1003183.

18. Eskenazi B, Marks AR, Bradman A, Harley K, Barr DB, Johnson C, Morga N, Jewell NP. Organophosphate pesticide exposure and neurodevelopment in young Mexican-American children. Environ Health Perspect. 2007;115(5): 792-8. doi:10.1289/ehp.9828.

19. Rauh VA, Garfinkel R, Perera FP, Andrews HF, Hoepner L, Barr DB, Whitehead $R$, Tang $D$, Whyatt RW. Impact of prenatal chlorpyrifos exposure on neurodevelopment in the first 3 years of life among inner-city children. Pediatrics. 2006:118:; doi:10.1542/peds.2006-0338.

20. Marks AR, Harley K, Bradman A, Kogut K, Barr DB, Johnson C, Calderon N, Eskenazi B. Organophosphate pesticide exposure and attention in young Mexican-American children: the CHAMACOS study. Environ Health Perspect. 2010;118(12):1768-74. doi:10.1289/ehp.1002056.

21. Bouchard MF, Chevrier J, Harley KG, Kogut K, Vedar M, Calderon N, Trujillo C, Johnson C, Bradman A, Barr DB, Eskenazi B. Prenatal exposure to organophosphate pesticides and IQ in 7-year-old children. Environ Health Perspect. 2011;119(8):1189-95. doi:10.1289/ehp.1003185.

22. Rauh V, Arunajadai S, Horton M, Perera F, Hoepner L, Barr DB, Whyatt R. Environ Health Perspect. 2011;119(8):1196-201.

23. Horton MK, Kahn LG, Perera F, Barr DB, Rauh V. Does the home environment and the sex of the child modify the adverse effects of prenatal exposure to chlorpyrifos on child working memory? Neurotoxicol Teratol. 2012;34(5):534-41. doi:10.1016/j.ntt.2012.07.004.

24. Furlong MA, Engel SM, Barr DB, Wolff MS. Prenatal exposure to organophosphate pesticides and reciprocal social behavior in childhood. Environ Int. 2014;70:125-31. doi:10.1016/j.envint.2014.05.011.

25. Shelton JF, Hertz-Picciotto I, Pessah IN. Tipping the balance of autism risk: potential mechanisms linking pesticides and autism. Environ Health Perspect. 2012;120(7):944-51. doi:10.1289/ehp.1104553.

26. Yolton $K, X u$ Y, Sucharew $H$, Succop P, Altaye M, Popelar A, Montesano MA, Calafat AM, Khoury JC. Impact of low-level gestational exposure to organophosphate pesticides on neurobehavior in early infancy: a prospective study. Environ Health. 2013;12(1):79.

27. Engel SM, Bradman A, Wolff MS, Rauh VA, Harley KG, Yang JH, Hoepner LA, Barr DB, Yolton K, Vedar MG, Xu Y, Hornung RW, Wetmur JG, Chen J, Holland NT, Perera FP, Whyatt RM, Lanphear BP, Eskenazi B. Prenatal organophosphorus pesticide exposure and child neurodevelopment at 24 months: an analysis of four birth cohorts. Environ Health Perspect. 2016; 124(6):822-30. doi:10.1289/ehp.1409474.

28. Donauer S, Altaye M, Xu Y, Sucharew H, Succop P, Calafat AM, Khoury JC, Lanphear B, Yolton K. An observational study to evaluate associations between Low-level gestational exposure to organophosphate pesticides and cognition during early childhood. Am J Epidemiol. 2016;184(5):410-8. doi:10.1093/aje/kwv447. 
29. Dam K, Seidler FJ, Slotkin TA: Chlorpyrifos exposure during a critical neonatal period elicits gender-selective deficits in the development of coordination skills and locomotor activity. Brain Res Dev Brain Res. 2000; 121:; doi:10.1016/S0165-3806(00)00044-4.

30. Ricceri L, Venerosi A, Capone F, Cometa MF, Lorenzini P, Fortuna S, Calamandrei G: Developmental neurotoxicity of organophosphorous pesticides: fetal and neonatal exposure to chlorpyrifos alters sex-specific behaviors at adulthood in mice. Toxicol Sci. 2006;93:; doi:10.1093/toxsci/kfl032.

31. Venerosi A, Ricceri L, Scattoni ML, Calamandrei G. Prenatal chlorpyrifos exposure alters motor behavior and ultrasonic vocalization in cd-1 mouse pups. Environ Health. 2009;8(1):12

32. Mullen BR, Khialeeva E, Hoffman DB, Ghiani CA, Carpenter EM. Decreased reelin expression and organophosphate pesticide exposure alters mouse behaviour and brain morphology. ASN Neuro. 2012;5(1):e00106. doi:10.1042/AN20120060.

33. Rice D, Barone Jr S. Critical periods of vulnerability for the developing nervous system: evidence from humans and animal models. Environ Health Perspect. 2000;108 Suppl 3:511-33.

34. Ricceri L, Venerosi A, Capone F, Cometa MF, Lorenzini P, Fortuna S, Calamandrei G. Developmental neurotoxicity of organophosphorous pesticides: fetal and neonatal exposure to chlorpyrifos alters sex-specific behaviors at adulthood in mice. Toxicol Sci. 2006;93(1):105-13. doi:10.1093/ toxsci/kfl032.

35. Venerosi A, Tait S, Stecca L, Chiarotti F, De Felice A, Cometa MF, Volpe MT, Calamandrei G, Ricceri L. Effects of maternal chlorpyrifos diet on social investigation and brain neuroendocrine markers in the offspring - a mouse study. Environ Health. 2015;14:32-015-0019-6. doi:10.1186/s12940-015-0019-6.

36. Mattsson JL, Maurissen JP, Nolan RJ, Brzak KA. Lack of differential sensitivity to cholinesterase inhibition in fetuses and neonates compared to dams treated perinatally with chlorpyrifos. Toxicol Sci. 2000;53(2):438-46.

37. Braquenier JB, Quertemont E, Tirelli E, Plumier JC. Anxiety in adult female mice following perinatal exposure to chlorpyrifos. Neurotoxicol Teratol. 2010;32(2):234-9. doi:10.1016/j.ntt.2009.08.008.

38. Harley KG, Engel SM, Vedar MG, Eskenazi B, Whyatt RM, Lanphear BP, Bradman A, Rauh VA, Yolton K, Hornung RW, Wetmur JG, Chen J, Holland NT, Barr DB, Perera FP, Wolff MS. Prenatal exposure to organophosphorous pesticides and fetal growth: pooled results from four longitudinal birth cohort studies. Environ Health Perspect. 2016;124(7):1084-92. doi:10.1289/ehp.1409362.

39. Lu C, Barr DB, Pearson MA, Waller LA. Dietary intake and its contribution to longitudinal organophosphorus pesticide exposure in urban/suburban children. Environ Health Perspect. 2008;116(4):537-42. doi:10.1289/ehp.10912.

40. Zhang Y, Han S, Liang D, Shi X, Wang F, Liu W, Zhang L, Chen L, Gu Y, Tian $Y$. Prenatal exposure to organophosphate pesticides and neurobehavioral development of neonates: a birth cohort study in Shenyang, China. PLoS One. 2014;9(2):e88491. doi:10.1371/journal.pone.0088491.

41. Coronado GD, Thompson B, Griffith WC. Children's exposure to OP pesticides: response to fenske et al. Environ Health Perspect. 2004;112(15):A866.

42. Baron-Cohen S. The extreme male brain theory of autism. Trends Cogn Sci. 2002;6(6):248-54.

43. Panksepp JB, Lahvis GP. Social reward among juvenile mice. Genes Brain Behav. 2007;6(7):661-71.

44. Panksepp JB, Wong JC, Kennedy BC, Lahvis GP. Differential entrainment of a social rhythm in adolescent mice. Behav Brain Res. 2008;195(2):239-45. doi:10.1016/j.bbr.2008.09.010.

45. Chadman KK. Fluoxetine but not risperidone increases sociability in the BTBR mouse model of autism. Pharmacol Biochem Behav. 2011;97(3):58694. doi:10.1016/j.pbb.2010.09.012.

46. MacFabe DF, Cain NE, Boon F, Ossenkopp KP, Cain DP. Effects of the enteric bacterial metabolic product propionic acid on object-directed behavior, social behavior, cognition, and neuroinflammation in adolescent rats: Relevance to autism spectrum disorder. Behav Brain Res. 2011;217(1):47-54. doi:10.1016/j.bbr.2010.10.005

47. Murray SA, Morgan JL, Kane C, Sharma Y, Heffner CS, Lake J, Donahue LR. Mouse gestation length is genetically determined. PLoS One. 2010;5(8): e12418. doi:10.1371/journal.pone.0012418.

48. Hill MA. Embryology Mouse Development. 2017. Retrieved April 28, 2017, from https://embryology.med.unsw.edu.au/embryology/index.php/Mouse_ Development.

49. Clancy B, Darlington RB, Finlay BL. Translating developmental time across mammalian species. Neuroscience. 2001;105(1):7-17.

50. Nadler JJ, Moy SS, Dold G, Trang D, Simmons N, Perez A, Young NB, Barbaro RP, Piven J, Magnuson TR, Crawley JN. Automated apparatus for quantitation of social approach behaviors in mice. Genes Brain Behav. 2004; 3(5):303-14. doi:10.1111/j.1601-183X.2004.00071.x.

51. Moy SS, Nadler JJ, Magnuson TR, Crawley JN. Mouse models of autism spectrum disorders: the challenge for behavioral genetics. Am J Med Genet C Semin Med Genet. 2006;142C(1):40-51. doi:10.1002/ajmg.c.30081.

52. Moy SS, Nadler JJ, Young NB, Nonneman RJ, Grossman AW, Murphy DL, D'Ercole AJ, Crawley JN, Magnuson TR, Lauder JM. Social approach in genetically engineered mouse lines relevant to autism. Genes Brain Behav. 2009;8(2):129-42. doi:10.1111/j.1601-183X.2008.00452.x.

53. Ennaceur A, Delacour J. A new one-trial test for neurobiological studies of memory in rats. 1: behavioral data. Behav Brain Res. 1988;31(1):47-59. https://doi.org/10.1016/0166-4328(88)90157-X.

54. Engel SM, Berkowitz GS, Barr DB, Teitelbaum SL, Siskind J, Meisel SJ, Wetmur JG, Wolff MS. Prenatal organophosphate metabolite and organochlorine levels and performance on the brazelton neonatal behavioral assessment scale in a multiethnic pregnancy cohort. Am J Epidemiol. 2007;165(12): 1397-404. doi:10.1093/aje/kwm029.

55. Bhat AN, Landa RJ, Galloway JC. Current perspectives on motor functioning in infants, children, and adults with autism spectrum disorders. Phys Ther. 2011;91(7):1116-29. doi:10.2522/ptj.20100294.

56. Brodkin ES, Hagemann A, Nemetski SM, Silver LM. Social approachavoidance behavior of inbred mouse strains towards DBA/2 mice. Brain Res. 2004;1002(1-2):151-7. doi:10.1016/j.brainres.2003.12.013.

57. Crawley JN, Chen T, Puri A, Washburn R, Sullivan TL, Hill JM, Young NB, Nadler $J$ J, Moy SS, Young $\sqcup$, Caldwell HK, Young WS. Social approach behaviors in oxytocin knockout mice: comparison of two independent lines tested in different laboratory environments. Neuropeptides. 2007;41(3):145-63.

58. Jamain S, Radyushkin K, Hammerschmidt K, Granon S, Boretius S, Varoqueaux F, Ramanantsoa N, Gallego J, Ronnenberg A, Winter D, Frahm J, Fischer J, Bourgeron T, Ehrenreich H, Brose N. Reduced social interaction and ultrasonic communication in a mouse model of monogenic heritable autism. Proc Natl Acad Sci U S A. 2008;105(5):1710-5. doi:10.1073/pnas.0711555105.

59. Venerosi A, Cutuli D, Colonnello V, Cardona D, Ricceri L, Calamandrei G. Neonatal exposure to chlorpyrifos affects maternal responses and maternal aggression of female mice in adulthood. Neurotoxicol Teratol. 2008;30:468-74.

60. Levin ED, Addy N, Nakajima A, Christopher NC, Seidler FJ, Slotkin TA: Persistent behavioral consequences of neonatal chlorpyrifos exposure in rats. Brain Res Dev Brain Res. 2001;130:; doi:10.1016/S0165-3806(01)00215-2.

61. Slotkin TA, Seidler FJ, Fumagalli F. Exposure to organophosphates reduces the expression of neurotrophic factors in neonatal rat brain regions: similarities and differences in the effects of chlorpyrifos and diazinon on the fibroblast growth factor superfamily. Environ Health Perspect. 2007;115(6): 909-16. doi:10.1289/ehp.9901.

62. Sala M, Braida D, Lentini D, Busnelli M, Bulgheroni E, Capurro V, Finardi A, Donzelli A, Pattini L, Rubino T, Parolaro D, Nishimori K, Parenti M, Chini B. Pharmacologic rescue of impaired cognitive flexibility, social deficits, increased aggression, and seizure susceptibility in oxytocin receptor null mice: a neurobehavioral model of autism. Biol Psychiatry. 2011;69(9):875-82. doi:10.1016/j.biopsych.2010.12.022.

63. Pobbe RL, Pearson BL, Defensor EB, Bolivar VJ, Young 3rd WS, Lee HJ, Blanchard DC, Blanchard RJ. Oxytocin receptor knockout mice display deficits in the expression of autism-related behaviors. Horm Behav. 2012; 61(3):436-44. doi:10.1016/j.yhbeh.2011.10.010.

64. Tait S, Ricceri L, Venerosi A, Maranghi F, Mantovani A, Calamandrei G: Longterm effects on hypothalamic neuropeptides after developmental exposure to chlorpyrifos in mice. Environ Health Perspect. 2009;117:; doi:10.1289/ehp.11696.

65. Persico AM, Bourgeron T. Searching for ways out of the autism maze: genetic, epigenetic and environmental clues. Trends Neurosci. 2006;29(7):349-58.

66. Rauh VA, Perera FP, Horton MK, Whyatt RM, Bansal R, Hao X, Liu J, Barr DB, Slotkin TA, Peterson BS. Brain anomalies in children exposed prenatally to a common organophosphate pesticide. Proc Natl Acad Sci U S A. 2012; 109(20):7871-6. doi:10.1073/pnas.1203396109.

67. Laviola G, Adriani W, Gaudino C, Marino R, Keller F. Paradoxical effects of prenatal acetylcholinesterase blockade on neuro-behavioral development and drug-induced stereotypies in reeler mutant mice. Psychopharmacology (Berl). 2006;187(3):331-44. doi:10.1007/s00213-006-0426-z.

68. Venerosi A, Ricceri L, Tait S, Calamandrei G. Sex dimorphic behaviors as markers of neuroendocrine disruption by environmental chemicals: the case of chlorpyrifos. Neurotoxicology. 2012;33(6):1420-6. doi:10.1016/j.neuro.2012.08.009. 